\title{
DRIE-SI GAS CHROMATOGRAPHY COLUMNS: EFFICIENCY AND THERMAL STABILITY OF STATIONARY PHASES FOR COMPREHENSIVE TWO-DIMENSIONAL (GCXGC) SEPARATIONS
}

\author{
G. Serrano, ${ }^{l}$ S. M. Reidy, ${ }^{2}$ K. D. Wise, ${ }^{3}$ and E. T. Zellers ${ }^{1,2^{*}}$
}

Center for Wireless Integrated Microsystems (WIMS), Departments of ${ }^{1}$ Environmental Health Sciences, ${ }^{2}$ Chemistry, and ${ }^{4}$ Electrical Engineering and Computer Sciences, University of Michigan, Ann Arbor, MI, USA

\begin{abstract}
This study addresses some of the most critical factors affecting the performance of DRIE-Si/glass channels used as gas chromatographic (GC) separation microcolumns, namely, the consistency and uniformity of stationary phase deposition, deactivation of surface-adsorption sites on the microcolumn walls, and the stability of the stationary phase following repeated thermal cycling. Here, we demonstrate that films of PDMS can be reliably and reproducibly deposited in microcolumns 0.5 to $3-\mathrm{m}$ long to provide unprecedented levels of separation efficiency and stable performance even up to $240^{\circ} \mathrm{C}$ in air. Use of HMDS as a surface deactivation agent is also demonstrated. The implementation of series-coupled microcolumns for comprehensive two-dimensional (GCxGC) separations employing pneumatic and thermal modulation at the junction point is also reported.
\end{abstract}

\section{INTRODUCTION}

The measurement of gases and vapors in complex mixtures is critical to numerous efforts in public health and homeland security, including human exposure assessments, threat detection, air quality forecasting, and biomedical diagnoses. Current instrumentation is too large and expensive for routine implementation in many such applications. It is now well-known that stand-alone microsensor arrays can be used for the determination of only very simple mixtures $[1,2]$ and, while progress continues toward microspectrometers capable of multi-component analysis [3-6], reliable quantitative analysis of complex gas/vapor mixtures demands temporal/spatial separation prior to measurement, regardless of the detector employed.

Several reports have appeared over the past decade on micromachined gas chromatographic $(\mu \mathrm{GC})$ separation columns coupled with one or another sampling, pretreatment and/or detection devices [7-17]. A typical structure consists of a $0.25-3-$ m-long deep-reactive-ion-etched (DRIE) $\mathrm{Si}$ channel with an anodically-bonded Pyrex cover plate [11], although other designs have been reported $[8,13]$. A polymer layer is deposited on the channel walls and reversible partitioning of vapor-phase chemicals into the layer as they progress down the column in a carrier gas results in spatial separation.

Although single-column $\mu \mathrm{GC}$ separations are the most common, dual-column configurations have also been reported [14]. Comprehensive, two-dimensional (GCxGC) chromatography represents a special case, in which compounds are partially separated on a longer first-dimension column having a stationary phase of one polarity and then focused and re-injected into a shorter second column coated with a stationary phase of different polarity using a thermal or pneumatic modulator at the junction point of the two columns [18]. It is well-suited for separating complex vapor mixtures. GCxGC chromatography using microcolumns has not been reported.

Among the factors that affect the chromatographic resolution achievable with microcolumns is the uniformity of the stationary phase deposited on the walls of the channel. This will significantly affect the number of theoretical plates $(\mathrm{N})$ per unit length, which is a standard measure of column efficiency that is related to chromatographic resolution. Deactivation of surface silanols on column walls is also important, as is the thermal stability of the stationary phase because temperature programming is typically used to accelerate separations.

This article examines the reproducibility achievable from multiple microfabricated GC columns statically coated with PDMS. The thermal stability of the PDMS stationary phase in air and $\mathrm{He}$ carrier gases is characterized, and the passivation of channel walls to reduce peak tailing for polar compounds is demonstrated. The use of microfabricated columns for pneumatically and thermally modulated GCxGC separations is also presented.
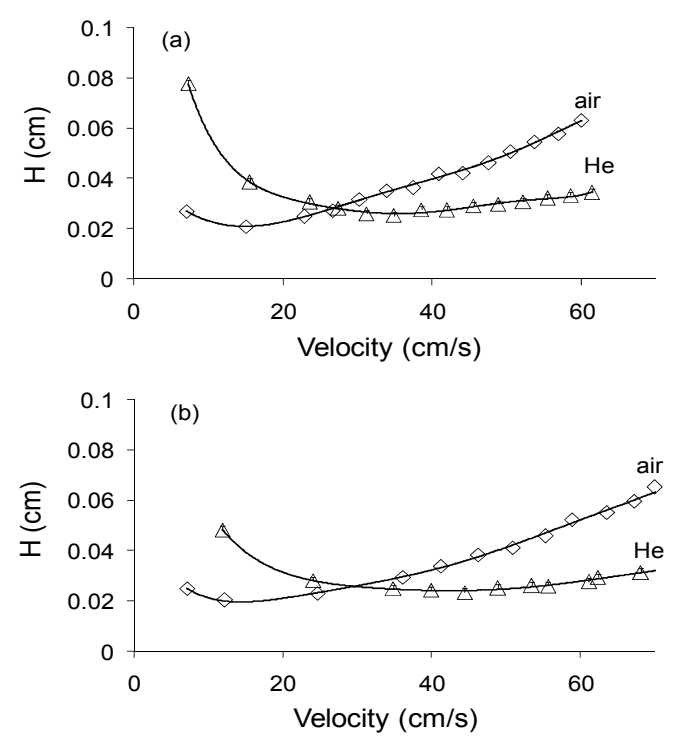

Figure 1. Golay plots (n-octane, $30{ }^{\circ} \mathrm{C}$ ) for (a) 3-m and (b) $1-m$ PDMS-coated microcolumns using He and air as carrier gas. For $\mathrm{He}$, the Golay plot is the average of five columns. For air, the plot is from a single column.

Table 1: Measures of efficiency for PDMS-coated microcolumns

\begin{tabular}{lcccc}
\hline & \multicolumn{2}{c}{$3-\mathrm{m}$ column } & \multicolumn{2}{c}{$1-\mathrm{m}$ column } \\
\cline { 2 - 5 }$N$ & $\mathrm{He}^{\mathrm{a}}$ & Air & $\mathrm{He}^{\mathrm{a}}$ & Air \\
$H_{\text {min }}(\mathrm{cm})$ & $12500(5)$ & 14400 & $4270(2)$ & 4950 \\
$u_{\text {opt }}(\mathrm{cm} / \mathrm{s})$ & $0.024(8)$ & 0.021 & $0.023(2)$ & 0.021 \\
${ }^{\text {a }}$ Average values, $\mathrm{n}=5 ;$ RSD $(\%)$ is given parentheses. & \\
\hline
\end{tabular}

Solid-State Sensors, Actuators, and Microsystems Workshop 


\section{EXPERIMENTAL SECTION Microfabricated Columns}

The microcolumn fabrication and stationary-phase deposition methods used in this study have been described previously $[11,12,15]$. Rectangular channels, $150 \mu \mathrm{m}$ wide by $240 \mu \mathrm{m}$ deep, were formed in Si by DRIE. A Pyrex cover was anodically bonded to the lower Si wafer to seal the channels. The 3-m microcolumns have a $3.2-\mathrm{cm} \times 3.2-\mathrm{cm}$ footprint and the shorter microcolumns have correspondingly smaller footprints. Deactivated fused-silica capillaries $(100-\mu \mathrm{m}-\mathrm{id})$ used for fluidic interconnections were secured by epoxy or silicone adhesive.

Five 1-m-long columns and five 3-m-long columns were coated with PDMS (OV-1, Ohio Valley, Marietta, OH), using a static coating method that entails filling the channel with a solution of PDMS and a cross-linking agent (dicumyl peroxide) in a volatile solvent, sealing one end, and then evaporating the solvent under vacuum at constant temperature [15]. Each column was then heated to $180^{\circ} \mathrm{C}$ to cross-link the polymer. A similar procedure was used for coating the moderately polar polymer, poly(trifluoropropylmethy)siloxane (PTFPMS, OV-215, Ohio Valley) within microcolumns used for GCxGC separations. The calculated film thickness for both stationary phases was $0.15 \mu \mathrm{m}$. To passivate the channel walls, a plug of liquid hexamethyldisilazane (HMDS) was passed through the column under a flow of $\mathrm{N}_{2}$ gas. The column was then sealed, heated to $450{ }^{\circ} \mathrm{C}$ for $4 \mathrm{~h}$, flushed with dichloromethane, and dried under $\mathrm{N}_{2}$ prior to stationary phase deposition as described above [19].

\section{Column Evaluations}

Each column was evaluated using a bench-scale GC equipped with split-splitless injector, oven, and a flame-ionization detector (FID). For initial tests, n-octane was used as the probe vapor at a column temperature of $30^{\circ} \mathrm{C}$ with a carrier gas of $\mathrm{He}$ or air supplied from a compressed gas cylinder. Samples of n-octane vapor $(2.5-\mu \mathrm{L})$ were drawn by syringe from the headspace of vial containing the pure solvent and injected with a split ratio of 1050:1. Golay plots (linear velocity vs. theoretical plate height) were used to determine the minimum plate height, $\mathrm{H}_{\min }$, and optimal linear velocity, $\mathrm{u}_{\mathrm{opt}}$. Chromatograms were processed with Grams/32 software (Galactic Industries, Salem, NH) and Excel.

To test thermal stability, two 3-m PDMS-coated columns were heated to several discrete temperatures between $30^{\circ} \mathrm{C}$ and $250^{\circ} \mathrm{C}$ and held at that temperature for $24 \mathrm{hr}\left(\leq 100^{\circ} \mathrm{C}\right)$ or $48 \mathrm{hr}\left(>100^{\circ} \mathrm{C}\right)$ with $\mathrm{He}$ or air flowing through the column. Following each temperature excursion, the columns were cooled down to $30^{\circ} \mathrm{C}$ and chromatograms were run in a $\mathrm{He}$ or air carrier gas on separate mixtures of five alkanes, three aromatics, four ketones, and four alcohols by injecting a $0.1-\mu \mathrm{L}$ liquid sample of each mixture. The peak capacity, which is the number of peaks that can be separated in a specified amount of time at a specified resolution, was used as the metric of performance. It varies with $\mathrm{N}^{1 / 2}$ and, at a given column temperature, is a measure of column efficiency.

GCxGC separations were performed using split syringe injections, a 3-m PDMS microcolumn in series with a $0.5-\mathrm{m}$ PTFPMS microcolumn, and an FID. For pneumatic modulation, a valve teed into the junction point of the two columns and connected to the carrier gas was used to equalize the pressure across the first column, thereby stopping flow in that column, while increasing the pressure at the junction point and the flow rate through the second column. Toggling this valve while a peak is eluting through the junction point allows for portions of the peak to be injected sequentially onto the second column and separated rapidly. A 2-D contour plot can be produced based on the retention time on each column. For thermal modulation, the junction-point valve was replaced by a two-stage meso-scale device that uses forced-air cooling and resistive heating to sequentially focus peaks eluting from the first column and re-inject them piecemeal onto the second column [20]. The temperature range of the thermal modulator is -25 to $\sim 200^{\circ} \mathrm{C}$ and peak widths of $80-100 \mathrm{~ms}$ can be generated.

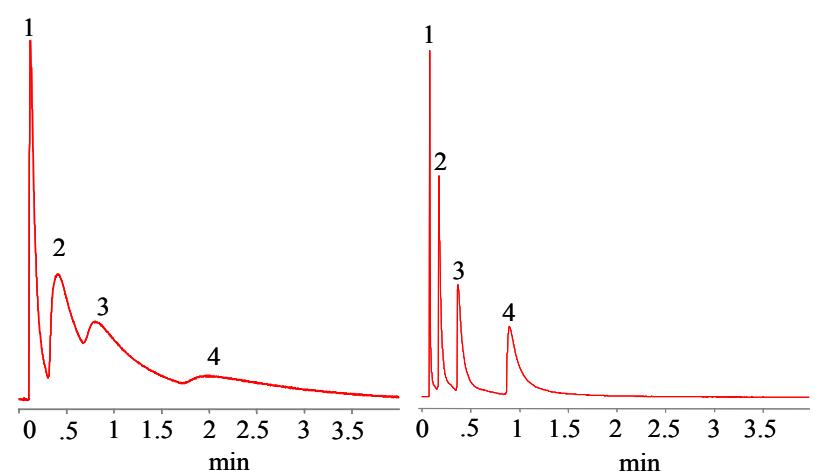

Figure 2. Chromatograms from untreated (left) and HMDS pretreated (right) 0.5-m PDMS-coated microcolumns for a mixture of alcohols: 1. 2-propanol, 2. 1-pentanol, 3. 1-hexanol, 4. 1heptanol.

\section{RESULTS AND DISCUSSION Reproducibility of Coating Deposition}

Figure 1 shows Golay plots for the 1-m and 3-m PDMS-coated columns using He and air carrier gases. Key metrics are presented in Table 1. Retention factors were 3.7 and 2.6 for the 3-m and $1-\mathrm{m}$ columns, respectively, ensuring sufficient retention under the test conditions to obtain reliable measures of efficiency. The plate production is extremely reproducible, with RSD values of $<5 \%$ for five replicates of each type of column. The $\mathrm{N}$ values of $\sim 4,250$ and $\sim 4,900$ plates/meter (for both the 1-m and 3-m columns) in $\mathrm{He}$ and air, respectively, are somewhat higher than those reported by Reidy et al. [17]. Part of this increase can be attributed to the higher split ratio used here. The calculated peak capacities (based on n-nonane in $\mathrm{He}$ ) were 28 and 54 for the $1-\mathrm{m}$ and $3-\mathrm{m}$ columns, respectively. Although higher $\mathrm{N}$ values are produced in air, using He allows higher velocities (flow rates) to be used without loss of resolution, which reduces overall analysis times. These results demonstrate highly reproducible deposition of uniform films of stationary phase in microcolumns.

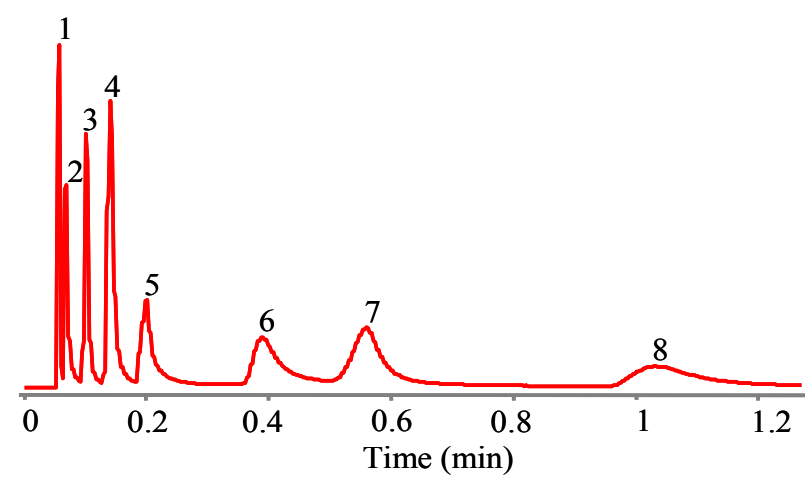

Figure 3. Test chromatogram of a multifunctional 8-component mixture separated isothermally at $30{ }^{\circ} \mathrm{C}$ using a 0.5-m HMDSpretreated PDMS-coated microcolumn. Compounds: 1 pentane; 2 2-propanol; 3 n-heptane; 4 toluene; 5 1-pentanol; 63 heptanone; 7 2-chlorotoluene; 8 2-octanone. 

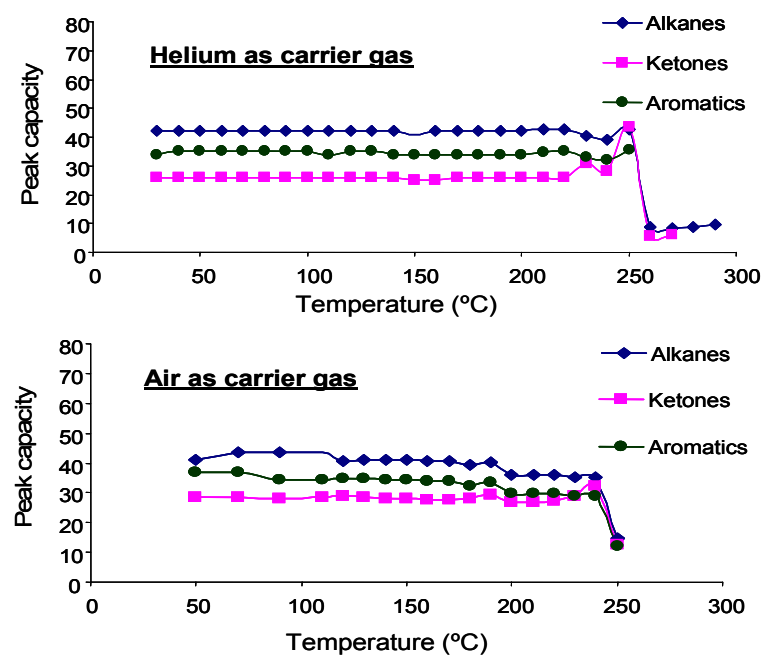

Figure 4. Peak capacity for different vapor subsets measured at $30{ }^{\circ} \mathrm{C}$ after pre-conditioning at the indicated temperature for 24-48 hrs, illustrating that the stationary phase is stable up to $240{ }^{\circ} \mathrm{C}$ in air or $\mathrm{He}$.

\section{Column Deactivation}

Although pretreatment is not necessary for achieving good separations of non-polar compounds [12,17], polar compounds interact with surface silanols on the channel walls, which degrades resolution. Pre-treatment with HMDS converts surface hydroxyl groups to trimethylsilyl ethers, rendering the sites non-polar. The improvement in peak shapes for the polar test vapors is apparent from the chromatograms shown in Figure 2 for a series of lowmolecular-weight alcohols separated on 0.5-m PDMS-coated columns with and without pretreatment. The HMDS pre-treatment had no effect on the resolution of non-polar compounds or the total number of theoretical plates for the columns (not shown).

Figure 3 shows the separation of a mixture of alkanes, aromatics, ketones, and alcohols using the pre-treated $0.5-\mathrm{m}$ PDMS column. The highly symmetric and baseline-resolved peaks achieved for this multi-vapor mixture in $70 \mathrm{sec}$ illustrate the positive effect of the pre-treatment (note: post-treatment with HMDS vapor produces similar results without any apparent effect on the PDMS).

\section{Thermal Stability of PDMS-Coated Microcolumns}

High-temperature operation can lead to oxidative decomposition of the stationary phase polymer and subsequent loss of resolution [21]. Figure 4 shows that the columns are stable in $\mathrm{He}$ and air up to $240-250^{\circ} \mathrm{C}$. Above this temperature, peak capacity decreases significantly for all compounds. These results are very encouraging as they demonstrate the ability to ramp column temperatures to values high enough for rapid temperatureprogrammed separations of compounds that have very low vapor pressures at ambient temperature.

\section{GCxGC Separations}

Figure 5 shows the configuration of the GCxGC system. The mid-point modulator comprises either a valve connected to the carrier gas supply (air) or a thermal cryo-trap/heater. We have succeeded in implementing GCxGC separation modules with our DRIE-Si/glass microcolumns employing pneumatic and thermal modulation. Figure 6a shows a "one-dimensional" chromatogram without any modulation of a 13-component mixture chosen to intentionally have several co-elutions. Figure $6 \mathrm{~b}$ is a $2-\mathrm{D}$ contour plot of the pneumatically modulated 13-component chromatogram.
Since the two separations are independent of each other there is a significant increase in peak capacity and all 13 components are completely separated. A mixture of aliphatic and aromatic hydrocarbons of similar complexity was analyzed using a thermal modulator in place of the pneumatic modulator $\left(\mathrm{H}_{2}\right.$ carrier gas, 0.25-m-long second column), with similar results (data not shown).

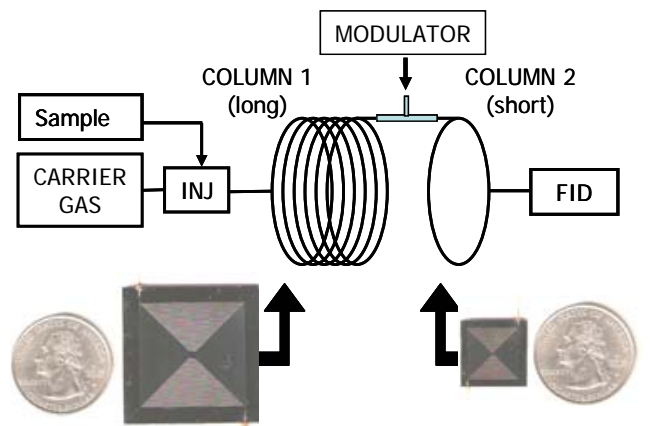

Figure 5. System configuration for comprehensive 2-D (GCxGC) separations using DRIE-Si microcolumns

(a)

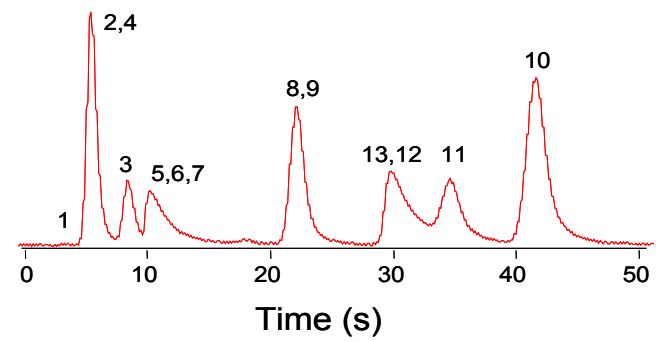

(b)

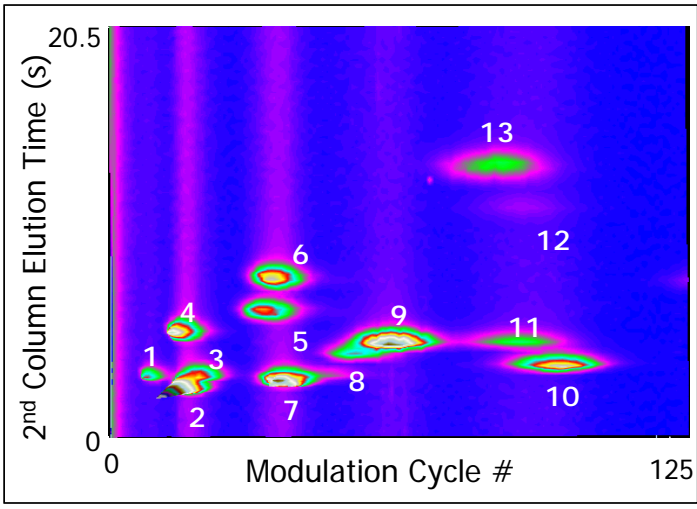

Figure 6. (a) One-dimensional chromatogram of a 13 component mixture. There are multiple sets of co-elutions. (b) A contour plot of the GCXGC separation of the 13 component mixture. The increase in peak capacity allows for the complete separation of all 13 components.

\section{CONCLUSIONS}

This work has established that DRIE-Si/glass microcolumns with statically coated and cross-linked stationary phases of PDMS can be made reproducibly and can provide highly efficient separations -- the values of $\mathrm{N}$ achieved in this study, up to 4,900 
plates/meter, are the highest values ever reported. Column pretreatment with HMDS was successful in dramatically reducing peak broadening associated with wall adsorption by polar analytes. The PDMS stationary phase was found to be stable to very high temperatures in air, which bodes well for using such microcolumns to separate compounds with very low vapor pressures (e.g., explosives, pesticides, etc.) in field applications using air as the carrier gas. Results shown here also confirm that comprehensive GCxGC separations can be performed with either thermal or pneumatic modulation using DRIE-Si/glass microcolumns.

\section{ACKNOWLEDGMENTS}

The authors wish to thank Ms. Katharine Beach for fabrication of the microcolumns employed here. This work was supported by the Engineering Research Center Program of the National Science Foundation under Award Number ERC-9986866 and by NASA Grant No. NNG06GA89G.

\section{REFERENCES}

[1] M.D. Hsieh, E.T. Zellers, "Limits of recognition for simple vapor mixtures determined with a microsensor array," Anal. Chem., 76, 1885 (2004).

[2] J.C. Jin, P. Kurzawski, A. Hierlemann, E.T. Zellers, "Evaluation of multitransducer arrays for the determination of organic vapor mixtures," Anal. Chem., 80, 227 (2008).

[3] R.A. Miller, E.G. Nazarov, G.A. Eiceman, A.T. King, "A MEMS radio-frequency ion-mobility spectrometer for chemical vapor detection," Sens. Actuat. A, 91, 301 (2001).

[4] C. Charlton, F. de Melas, A. Inberg, N. Croitoru, B. Mizaikoff, "Hollow-waveguide gas sensing with roomtemperature quantum cascade lasers," IEE Proc.Optoelect. 150, 306 (2003).

[5] F.G. Bessoth, O.P Naji, J.C.T Eijkel, A. Manz, "Towards an on-chip gas chromatograph: the development of a gas injector and a dc plasma emission detector," J. Anal. Atom. Spectrom. 17, 794 (2002).

[6] J. Moxom, P.T.A. Reilly, W.B. Whitten, J.M. Ramsey, "Analysis of VOCs in air with a micro ion trap mass analyzer," Anal. Chem, 75, 3739 (2003).

[7] A. deMello, "On-chip chromatography: the last twenty years," Lab on a Chip, 2, 48N (2002).

[8] H. Noh, P.J. Hesketh, G.C. Frye-Mason, "Parylene gas chromatographic column for rapid thermal cycling," IEEE J. Microelectromech. Syst., 11, 718 (2002).

[9] A. Bhushan, D. Yemane, D. Trudell, E.B. Overton, J. Goettert, "Fabrication of micro-gas chromatograph columns for fast chromatography," J. Microsyst. Tech., 13, 361 (2007).

[10] P.R. Lewis, R.P Manginell, D.R. Adkins, R.J. Kottenstette, D.R. Wheeler, S.S. Sokolowski, D.E. Trudell, J.E. Bymes, M. Okandan, J.M. Bauer, R.G. Manley, G.C. Frye-Mason, "Recent advancements in the gas-phase MicroChemLab," IEEE Sensors J., 6, 784 (2006).

[11] M. Agah, J.A. Potkay, G.R. Lambertus, R.D. Sacks, K.D. Wise, "High performance temperature-programmed microfabricated gas chromatography columns," IEEE J. Microelectromech. Syst., 14 (5), 1039 (2005).

[12] G.R. Lambertus, A. Elstro, K. Sensening, J. Potkay, M. Agah, S. Scheuering, K.D. Wise, F. Dorman, R. Sacks, "Design, fabrication, and microfabricated columns evaluation of for gas chromatography," Anal. Chem., 76, 2629 (2004).
[13] J.A Potkay, G.R. Lambertus, R.D. Sacks, K.D. Wise, “A lowpower pressure- and temperature-programmable micro gas chromatography column," IEEE J. Microelectromech. Syst., 16, 1071 (2007).

[14] C-J. Lu, W.H. Steinecker, W-C. Tian, M. Oborny, J. Nichols, M. Agah, J.A. Potkay, H.K. Chan, J. Driscoll, R.D. Sacks, K.D. Wise, S. Pang, E.T. Zellers, "First-generation hybrid MEMS gas chromatograph," Lab on a Chip., 5, 1123 (2005).

[15] S. Reidy, G. Lambertus, J. Reece, R. Sacks, "Highperformance, static-coated silicon microfabricated columns for gas chromatography," Anal. Chem., 78, 2623 (2006).

[16] G.R. Lambertus, C. Fix, S.M. Reidy, R. Miller, D. Wheeler, E. Nazarov, R.D. Sacks, "Silicon microfabricated column with microfabricated differential mobility spectrometer for GC analysis of VOCs," Anal. Chem., 77, 7563 (2005).

[17] S. Reidy, D. George, M. Agah, R. Sacks, "Temperatureprogrammed GC using Si microfabricated columns with integrated heaters and temperature sensors," Anal. Chem., 79, 2911 (2007).

[18] M. Junge, S. Bieri, H. Huegel, and P. J. Marriott, "Fast comprehensive two-dimensional gas chromatography with cryogenic modulation," Anal. Chem., 79, 4448 (2007).

[19] R.C. Kong, G. Grob, "Deactivation of small diameter fusedsilica capillary columns for gas and supercritical fluid chromatography," Chromatographia, 18, 362 (1984).

[20] M. Libardoni, J. H. Waite, R. D. Sacks, "Electrically heated, air-cooled thermal modulator and at-column heating for comprehensive two-dimensional gas chromatography," Anal. Chem., 77, 2786 (2005).

[21] K. Grob, G. Grob, "Capillary columns with immobilized stationary phases. 5 . Determination of column bleeding - resilylation," J. HRC \& CC., 5, 349 (1982). 